\title{
Complexation of Poly(ethyleneimine)-Bound 8-Hydroxyquinoline with Palladium(II)
}

\author{
Rongnong Zhou and Kurt E. Geckeler* \\ Institute of Organic Chemistry, University of Tübingen, \\ Auf der Morgenstelle 18, D-W-7400 Tübingen \\ Z. Naturforsch. 47 b, 1300-1306 (1992); received April 28, 1992 \\ Complexation, 8-Hydroxyquinoline, Polymer-Bound, Oxine, Palladium Complex \\ The complexing behavior of poly(ethyleneimine) 5-sulfonyl-8-hydroxyquinoline (POX) \\ with palladium(II) ions in aqueous solution was studied by means of spectrophotometry in the \\ visible region. It was shown that poly(ethyleneimine) 5-sulfonyl-8-hydroxyquinoline forms a \\ stable, water-soluble, orange-colored complex which has a maximum absorption at a wave- \\ length of $424 \mathrm{~nm}$. The effect of $\mathrm{pH}$, concentration of poly(ethyleneimine) 5-sulfonyl- \\ 8-hydroxyquinoline, concentration of palladium(II) ions, and time were investigated. The re- \\ sults show that in a $\mathrm{pH}$ range between 2 and 5 , the absorbance is constant for 40 minutes. The \\ linear concentration range for palladium(II) ions was determined to be $0-2.5 \mu \mathrm{g} \cdot \mathrm{ml}^{-1}$ and the \\ molar extinction coefficients $1.06 \cdot 10^{4}\left(1 \cdot \mathrm{mol}^{-1} \cdot \mathrm{cm}^{-1}\right)$ for the polymeric derivative and \\ $7.15 \cdot 10^{3}$ for the monomeric 8-hydroxyquinoline. The effect of tartaric acid as a masking agent \\ was examined in order to eliminate the influence from other ions. The simultaneous presence \\ of $\mathrm{K}(\mathrm{I}), \mathrm{Cs}(\mathrm{I}), \mathrm{Li}(\mathrm{I}), \mathrm{Ba}(\mathrm{II}), \mathrm{Ca}(\mathrm{II}), \mathrm{Cd}(\mathrm{II}), \mathrm{Hg}(\mathrm{II}), \mathrm{Mn}(\mathrm{II}), \mathrm{Ni}(\mathrm{II}), \mathrm{Al}(\mathrm{III}), \mathrm{As}(\mathrm{III}), \mathrm{Au}(\mathrm{III})$, \\ $\mathrm{Cr}(\mathrm{III}), \mathrm{Fe}(\mathrm{III}), \mathrm{Pt}(\mathrm{IV}), \mathrm{As}(\mathrm{V})$ did not interfere with the complexation of poly(ethyleneimine) \\ 5-sulfonyl-8-hydroxyquinoline and palladium(II). However, it was found that $\mathrm{NH}_{4}{ }^{+}$interferes \\ strongly. The polymer 8 -hydroxyquinoline derivative exhibited a $45 \%$ higher sensitivity to \\ $\mathrm{Pd}(\mathrm{II})$ ions in comparison to the low-molecular-weight 8-hydroxyquinoline.
}

\section{Introduction}

The complexation of cross-linked polymers with metal ions has found broad interest in the past $[1-4]$. Soluble synthetic macromolecules have also found interest and applications in many areas [5-7]. Recently, it was shown that the complexation of polymers with metal ions depends on several parameters, such as type of polymer backbone, functional groups, $\mathrm{pH}$, ionic strength, and metal concentration [6-10].

A number of hydrophilic polymers were investigated and found to interact typically with a series of metal ions under various conditions. A salient example in terms of its properties and complexation profile is poly(ethyleneimine) which was found to complex many metal ions $[5,7,10]$. The high solubility and strong hydrophilicity of this polymer makes it suitable for complexation studies in aqueous solution. The trifunctional moieties incorporated into the macromolecule provide an additional broad functional interaction spectrum. To increase the selectivity of the polymer reagent it is

\footnotetext{
* Reprint requests to Priv.-Doz. Dr. K. E. Geckeler.

Verlag der Zeitschrift für Naturforschung,

D-W-7400 Tübingen

0932-0776/92/0900-1300/\$01.00/0
}

necessary to introduce selective functional groups with a special complexing capability.

8-Hydroxyquinoline (oxine) is known as a chromogenic analytical low-molecular reagent with a high complexing affinity to certain metal ions, particularly to multicharged ions [12-14]. Besides attachment of this reagent to polymeric resins it has been employed as a functional group of soluble polymer reagents, called polychelatogens $[9,11]$. This compound introduced as a ligand into macromolecules retained its unique complexing capacity with metal ions also in the polymeric form. The 8-hydroxyquinoline polymer complexes not only with many transition and heavy metals at different $\mathrm{pH}$ but forms also complexes with actinides [15]. However, palladium(II) was not yet amongst the metals studied in conjuction with 8-hydroxyquinoline polymers.

In this paper, the complexation of poly(ethyleneimine)-bound 8-hydroxyquinoline (POX) with palladium(II) was investigated in aqueous solution with regard to several parameters using spectrophotometry in the visible region.

\section{Materials and Method}

Materials: All salts were analytical grade and used as received. Palladium(II) was used in the 
form of an atomic absorption spectrophotometry standard solution $\left(1,000 \mathrm{mg} \cdot 1^{-1}\right.$ of $\mathrm{Pd}(\mathrm{II})$ in hydrochloric acid (5 wt.-\%); Alfa Morton Thiokol, Danvers, USA). Poly(ethyleneimine) ( $\overline{\mathrm{M}} 30,000-$ $40,000 \mathrm{~g} \cdot \mathrm{mol}^{-1}$; BASF, Germany), and the other reagents were used without further purification.

Preparation of poly(ethyleneimine) 5-sulfonyl8-hydroxyquinoline: Poly(ethyleneimine) 5-sulfonyl-8-hydroxyquinoline (POX) (Fig. 1) was obtained by reaction of poly(ethyleneimine) (PEI) and 8-hydroxyquinoline-5-sulfonic acid chloride $[5,9,11]$. The content of 8-hydroxyquinoline5 -sulfonyl groups was $8.3 \mathrm{~mol}-\%$ (calculated from elemental analysis data, $\mathrm{S}=1.28 \%$ ). IR-spectrum $(\mathrm{KBr}): \approx 3400\left(-\mathrm{NH}_{2},-\mathrm{OH}\right), \approx 3200(-\mathrm{NH}-)$, $1750\left(-\mathrm{SO}_{2}-\mathrm{NH}-\right), 1700\left(-\mathrm{NH}_{2},-\mathrm{NH}-\right), 1450$ $(-\mathrm{OH}), \quad 1400-1040 \quad\left(-\mathrm{SO}_{2}-\right), \quad 980,880,780$ $(=\mathrm{C}-\mathrm{H}) \mathrm{cm}^{-1} \cdot{ }^{1} \mathrm{H}$ NMR $\left(\mathrm{D}_{2} \mathrm{O}\right): \delta=8.297-7.899$ (aromatic group), 4.664 (HDO), 3.756-2.738 ( $>\mathrm{N}-\mathrm{CH}_{2}-,-\mathrm{NH}-\mathrm{CH}_{2}-, \mathrm{NH}_{2}-\mathrm{C}_{2}-$ ) ppm.

The complex-forming polymer was membrane filtrated prior to use. It was easily water-soluble, but insoluble in most organic solvents.

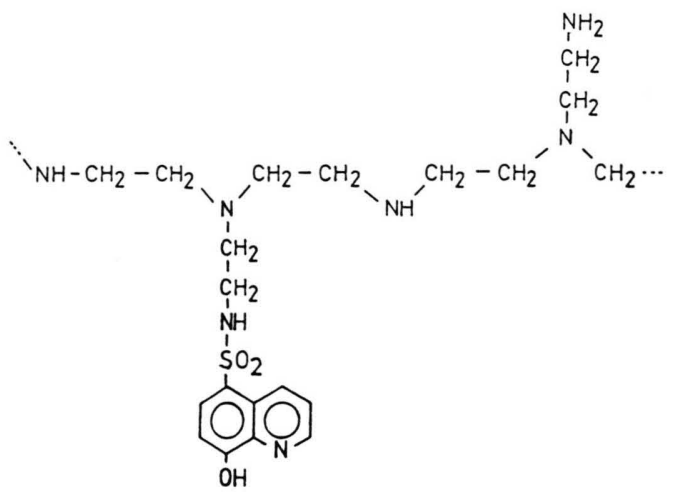

Fig. 1. Constitutional formula of the ligand unit of poly(ethyleneimine) 5-sulfonyl-8-hydroxyquinoline.

Measurements: Elemental analysis was performed with an elemental analyzer 1106 from Carlo Erba (Hofheim, Germany). IR spectra were recorded on a Bruker IFS-48 spectrophotometer and ${ }^{1} \mathrm{H}$ NMR spectra on a Bruker AC 250 spectrometer. A Lamda $5 \mathrm{UV} / \mathrm{VIS}$ spectrophotometer from Perkin-Elmer (Überlingen, Germany) served for the spectrophotometric studies.

\section{Complexation studies by spectrophotometry}

Procedure for the complexation study: A sample of the standard solution (10 $\mu \mathrm{g}$ palladium(II)) was transferred into a $10 \mathrm{ml}$ graduate flask and $2.0 \mathrm{ml}$ of a poly(ethyleneimine) 5-sulfonyl-8-hydroxyquinoline solution $(0.3 \mathrm{wt} .-\%)$ were added. $1.0 \mathrm{ml}$ of a solution of tartaric acid (5 wt.- $\%$ ) was added and the $\mathrm{pH}$ was adjusted to 4.0 with diluted hydrochloric acid. After filling up to the graduate mark with hydrochloric acid-acidified water $(\mathrm{pH}$ 4.0) and well mixing, the absorbance was measured at $424 \mathrm{~nm}$ in a $1 \mathrm{~cm}$ cuvette against reagent blank (Fig. 2).

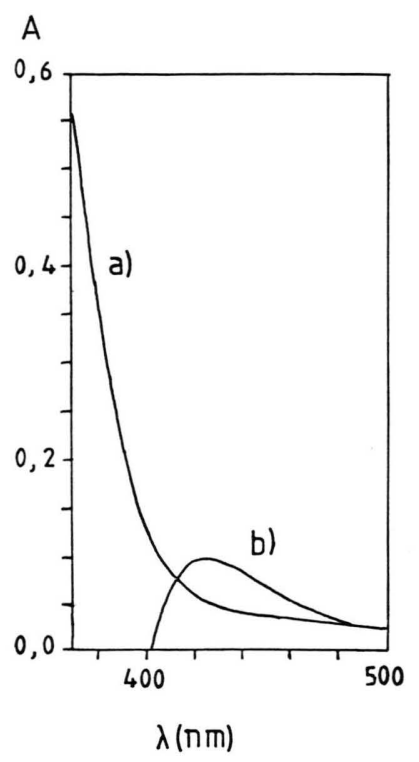

Fig. 2. Absorption spectra of poly(ethyleneimine) 5-sulfonyl-8-hydroxyquinoline and its complex with $\mathrm{Pd}(\mathrm{II})$ at $\mathrm{pH} 4.0$.

a) $0.01 \mathrm{wt} .-\%$ polymer solution against water.

b) $0.06 \mathrm{wt} .-\%$ polymer solution in the presence of $1.0 \mu \mathrm{g}$ $\mathrm{Pd}(\mathrm{II})$ against reagent blank.

Procedure for the $\mathrm{pH}$ effect study: A sample of $15 \mu \mathrm{g}$ palladium(II) was transferred into a $10 \mathrm{ml}$ graduate flask and $2.0 \mathrm{ml}$ of a poly(ethyleneimine) 5-sulfonyl-8-hydroxyquinoline solution $(0.3 \mathrm{wt} .-\%)$ were added. The $\mathrm{pH}$ value was adjusted to $1,2,3$, 4,5 , and 6 with diluted hydrochloric acid. After filling up to the graduate mark with diluted hydrochloric acid-acidified water and well mixing the absorbance was measured at $424 \mathrm{~nm}$ in a $1 \mathrm{~cm}$ cuvette against reagent blank (Fig. 3).

Procedure for the polymer concentration study: A sample of $15 \mu \mathrm{g}$ palladium(II) was transferred into a $10 \mathrm{ml}$ graduate flask and $0.5,1.0,1.5,2.0$, 2.5 , and $3.0 \mathrm{ml}$, respectively, of a poly(ethyleneimine) 5-sulfonyl-8-hydroxyquinoline solution 


\section{A}

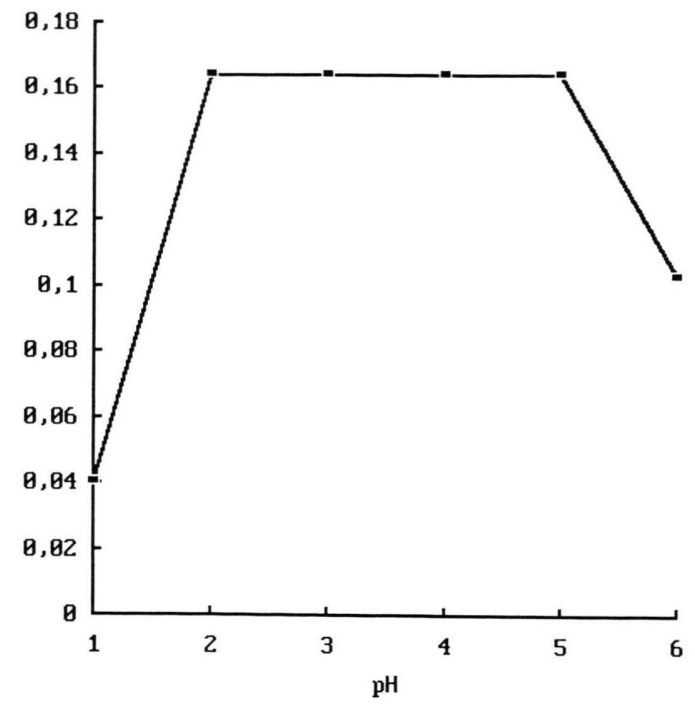

Fig. 3. $\mathrm{pH}$ variation of the absorbance of the $\mathrm{Pd}(\mathrm{II})$ complex of poly(ethyleneimine) 5-sulfonyl-8-hydroxyquinoline against reagent blank (1.5 $\mu \mathrm{g} \mathrm{Pd(II),} 0.06$ wt.$\%$ of polymer solution).
$(0.3$ wt.- $\%)$ were added. The $\mathrm{pH}$ was adjusted to 4.0 with diluted hydrochloric acid. After filling up to the graduate mark with hydrochloric acid-acidified water $(\mathrm{pH} 4)$ and well mixing the absorbance was measured at $424 \mathrm{~nm}$ in a $1 \mathrm{~cm}$ cuvette against reagent blank (Fig. 4).

Procedure for the tartaric acid effect study: A sample of $15 \mu \mathrm{g}$ palladium(II) was transferred into a $10 \mathrm{ml}$ graduate flask and $2.0 \mathrm{ml}$ of a poly(ethyleneimine) 5-sulfonyl-8-hydroxyquinoline solution (0.3 wt.- $\%)$ were added. $0,0.5,1.0,1.5,2.0,2.5$, and $3.0 \mathrm{ml}$, respectively, of a $5 \mathrm{wt} .-\%$ solution of tartaric acid were added and the $\mathrm{pH}$ was adjusted to 4 with diluted hydrochloric acid. After filling up to the graduate mark with hydrochloric acid-acidified water $(\mathrm{pH} 4)$ and well mixing the absorbance was measured at $424 \mathrm{~nm}$ in a $1 \mathrm{~cm}$ cuvette against reagent blank (Fig. 5).

Procedure for palladium(II) concentration study: A sample of $0,5,15,20,25$, and $30 \mu \mathrm{g}$ of, respectively, palladium(II) was transferred into a $10 \mathrm{ml}$ graduate flask, and $2.0 \mathrm{ml}$ of a poly(ethyleneimine) 5-sulfonyl-8-hydroxyquinoline solution $(0.3 \mathrm{wt} .-\%)$ were added. $1.0 \mathrm{ml}$ of a $5 \mathrm{wt} .-\%$ tartaric acid was added and the $\mathrm{pH}$ was adjusted to 4 with diluted hydrochloric acid. After filling up to the graduate mark with hydrochloric acid-acidified water $(\mathrm{pH} 4)$ and well mixing the absorbance

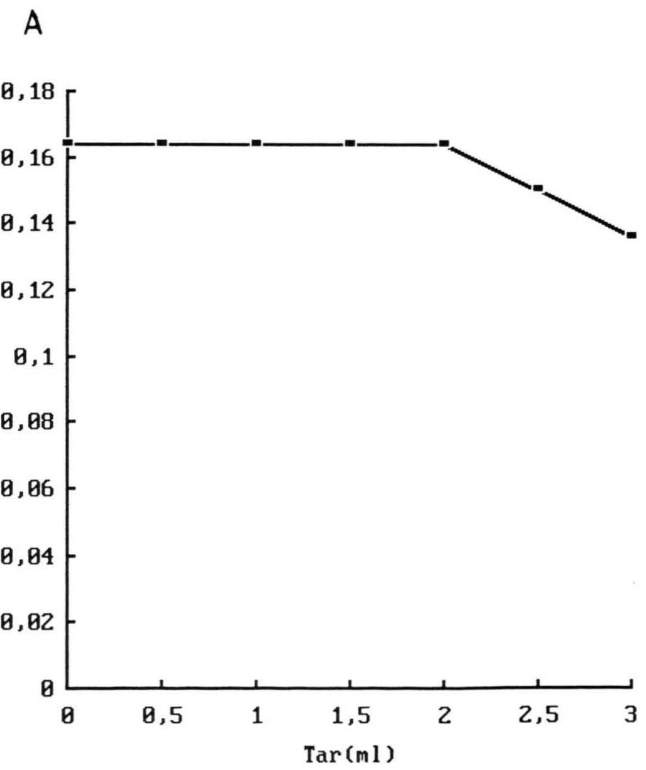

Fig. 5. Plot of the absorbance of the Pd(II)-complex of poly(ethyleneimine) 5-sulfonyl-8-hydroxyquinoline on tartaric acid (Tar) concentration against reagent blank (1.5 $\mu \mathrm{g} \mathrm{Pd}(\mathrm{II}), 0.06 \mathrm{wt} .-\%$ of polymer solution, $\mathrm{pH} 4.0$ ). complex of poly(ethyleneimine) 5-sulfonyl-8-hydrox quinoline on the polymer concentration $(\mathrm{P}-\mathrm{OX})$ against reagent blank (1.5 $\mu \mathrm{g} \mathrm{Pd}(\mathrm{II}), \mathrm{pH} 4)$.

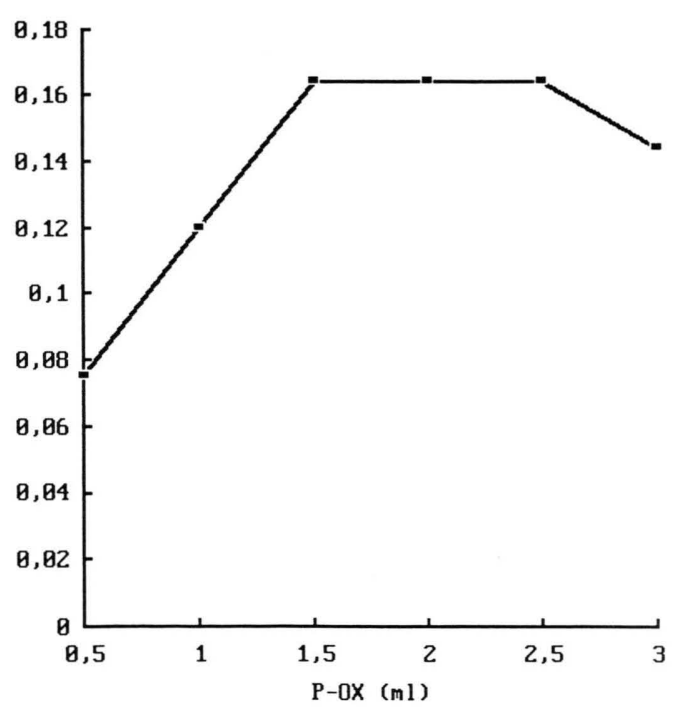

Fig. 4. Dependence of the absorbance of the Pd(II)- 


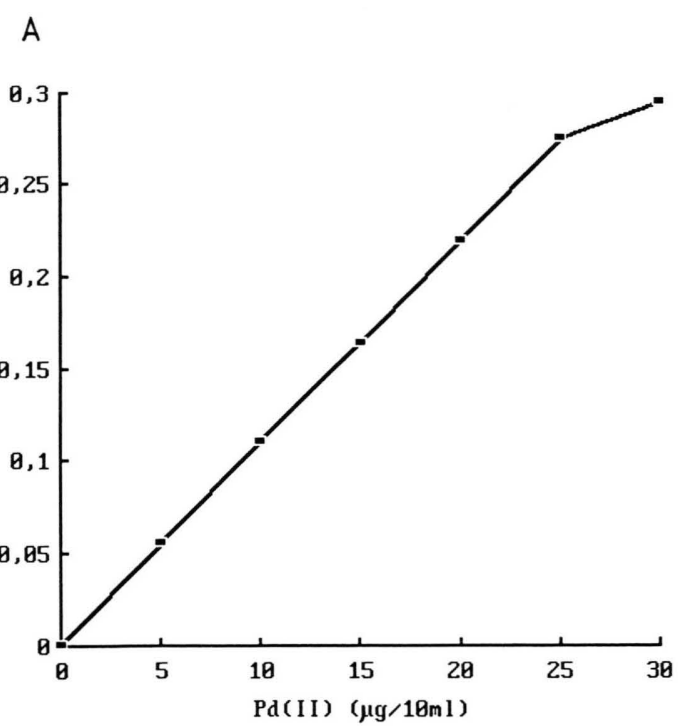

Fig. 6. Dependence of the absorbance of the $\mathrm{Pd}(\mathrm{II})$ complex of poly(ethyleneimine) 5-sulfonyl-8-hydroxyquinoline from the concentration of $\mathrm{Pd}(\mathrm{II})$ against reagent blank $(0.06 \%$ wt.- $\%$ of polymer solution).

\section{A}

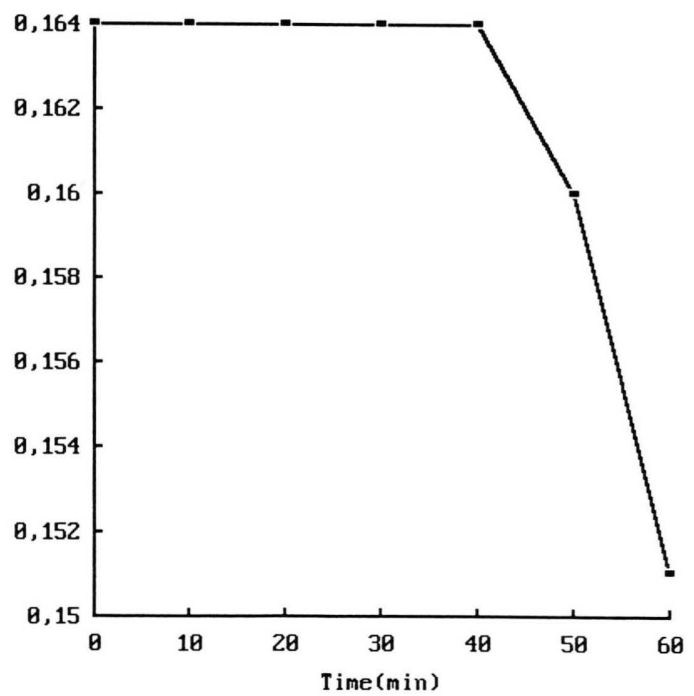

Fig. 7. Effect of time on the complex formation of poly(ethyleneimine) 5-sulfonyl-8-hydroxyquinolane with $\mathrm{Pd}(\mathrm{II})$ against reagent blank (1.5 $\mu \mathrm{g} \mathrm{Pd}(\mathrm{II}), 0.06$ wt.- $\%$ of polymer solution, 0.5 wt.- $\%$ tartaric acid, $\mathrm{pH}$ 4.0). was measured at $424 \mathrm{~nm}$ in a $1 \mathrm{~cm}$ cuvette against reagent blank (Fig. 6).

Procedure for the ion effect studies: A sample of $15 \mu \mathrm{g}$ palladium(II) was transferred into a $10 \mathrm{ml}$ graduate flask and $2.0 \mathrm{ml}$ of a poly(ethyleneimine) 5-sulfonyl-8-hydroxyquinoline solution ( $0.3 \mathrm{wt} .-\%)$ were added. $1.0 \mathrm{ml}$ of a tartaric acid and the solution of a single additional ion was added. The $\mathrm{pH}$ was adjusted to 4 with diluted hydrochloric acid. After filling up to the graduated mark with hydrochloric acid-acidified water $(\mathrm{pH} \mathrm{4.0)}$ and well mixing the absorbance was measured at $424 \mathrm{~nm}$ in a $1 \mathrm{~cm}$ cuvette against reagent blank (Fig. 7).

\section{Results and Discussion}

The complex forming derivative of poly(ethyleneimine) was synthesized by the acylation reaction of 8-hydroxyquinoline-5-sulfonic acid chloride with poly(ethyleneimine). The content of 8-hydroxyquinoline-5-sulfonyl groups in the polymer was $8.3 \mathrm{~mol}-\%$. ${ }^{1} \mathrm{H}$ NMR spectrometric data of poly(ethyleneimine) (in $\mathrm{D}_{2} \mathrm{O}$ ), poly(ethyleneimine) 5-sulfonyl-8-hydroxyquinoline (POX) (in $\mathrm{D}_{2} \mathrm{O}$ ), and 8-hydroxyquinoline (in $\mathrm{CDCl}_{3}$ ) show that the POX contained both components. The IR spectra of POX with bands at $1400-1040$ $\left(-\mathrm{SO}_{2}-\right), 980,880$, and $780 \mathrm{~cm}^{-1}(=\mathrm{C}-\mathrm{H})$ indicated similar results. It was easily water-soluble, but insoluble in most organic solvents.

\section{Complexing properties of poly (ethyleneimine) 5-sulfonyl-8-hydroxyquinoline}

8-Hydroxyquinoline (oxine) is known for its outstanding complexing properties for multicharged metal ions. The covalent attachment of this ligand to the polymer backbone of poly(ethyleneimine) lead to easily water-soluble, functional macromolecules which exhibited interesting complexing properties [8, 10] (Fig. 1).

The complexing behavior of the poly(ethyleneimine) 8-hydroxyquinoline derivative with ten metal ions was investigated by membrane filtration $[6,9]$. The results of the retention of a various metal ions at a filtration factor $\mathrm{Z}$ of 10 and at different $\mathrm{pH}$ are shown in Table I.

The data show that the 8-hydroxyquinoline polymer exhibits a much higher retention capacity in 
Table I. Retention of a series of metal ions by poly(ethyleneimine) 5 -sulfonyl-8-hydroxyquinoline at different $\mathrm{pH}(2 \% \mathrm{polymer}$ solution, concentration of each metal ion: $20 \mu \mathrm{g} / \mathrm{ml}$, filtration factor $Z=10)^{\mathrm{a}}$.

\begin{tabular}{lllllllllllllllllllll}
\hline $\mathrm{pH}$ & $\mathrm{Al}^{3+}$ & $\mathrm{Ba}^{2+}$ & $\mathrm{Be}^{2+}$ & $\mathrm{Bi}^{3+}$ & $\mathrm{Cd}^{2+}$ & $\mathrm{Co}^{2+}$ & $\mathrm{Cr}^{3+}$ & $\mathrm{Cu}^{2+}$ & $\mathrm{Fe}^{3+}$ & $\mathrm{Hg}^{2+}$ & $\mathrm{K}^{+}$ & $\mathrm{Mn}^{2+}$ & $\mathrm{Nb}^{5+}$ & $\mathrm{Ni}^{2+}$ & $\mathrm{Pb}^{2+}$ & $\mathrm{V}^{5+}$ & $\mathrm{W}^{6+}$ & $\mathrm{Zn}^{2+}$ & $\mathrm{Zr}^{4+}$ \\
\hline 1 & - & 15 & - & 95 & - & - & 0 & 80 & 70 & 35 & 0 & - & 65 & 22 & 100 & 20 & 100 & - & 98 \\
3 & 25 & 25 & 0 & - & 0 & 95 & - & 100 & 95 & 75 & - & - & 100 & 42 & - & 78 & - & 0 & 98 \\
5 & 95 & 35 & 0 & - & 83 & 95 & 45 & - & 95 & 85 & 0 & 18 & 100 & 100 & - & 90 & 88 & 95 & 98 \\
7 & 85 & 40 & 55 & - & 98 & 95 & - & 100 & - & 95 & - & 100 & - & 100 & - & 100 & - & - & - \\
\hline
\end{tabular}

a Adopted from ref. [9].

acidic solution with respect to more highly charged metal ions, such as $\mathrm{Zr}, \mathrm{Nb}, \mathrm{W}, \mathrm{Bi}$, and can be used for separation of these metals from the other ions. At higher $\mathrm{pH}$, the water-soluble polymer can be applied to separate and preconcentrate many different metal ions.

\section{Spectrophotometric investigations}

The complexation properties of POX with a series of metal ions have been already studied. However, the complexation of this polymer with palladium(II) has not been investigated so far.

In order to evaluate the conditions for the complexation of poly(ethyleneimine) 5-sulfonyl8-hydroxyquinoline (POX) with palladium(II) ions, several parameters have been studied.

The absorption spectra of a solution of POX and its palladium(II) complex at $\mathrm{pH} 4$ are shown in Fig. 2.

The absorption spectrum of a POX solution shows no absorption maximum in the visible region, whereas the polymer solution after the mixing with palladium(II) ions exhibits an absorption maximum at $424 \mathrm{~nm}$. This indicates the formation of a polymer complex with the bivalent palladium. The complex was orange-colored, water-soluble and stable.

\section{Effect of $p H$}

In order to study the influence of $\mathrm{pH}$ on the complexation profile, the absorption spectra were recorded at several $\mathrm{pH}$ between 1 and 6 . The absorption maximum of the colored complex at 424 $\mathrm{nm}$ was found to be in the $\mathrm{pH}$ range between 2.0 and 5.0. That corresponds to the $\mathrm{pH}$ range in which a stable metal complex with the polymer ligand is formed (Fig. 3).

The absorbance within this $\mathrm{pH}$ range was practically not changed. This is in good agreement with data for the monomeric compound in literature [13]. Therefore, $\mathrm{pH} 4$ was chosen for the complexation studies. The comparison of several experimental values for the low-molecular-weight 8-hydroxyquinoline reagent and the corresponding polymer derivative is given in Table II.

\section{Effect of the polymer concentration}

The effect of the polymer concentration on the complexation of POX and palladium(II) ions was investigated as a further parameter. These results are shown in Fig. 4.

It is evident that there was no change and a maximum absorbance at $424 \mathrm{~nm}$ within the range of the addition of $1.5-2.5 \mathrm{ml}$ of $0.3 \mathrm{wt} .-\%$ POX. Therefore, a concentration of 0.06 wt.- $\%$ POX was chosen for the following experiments.

\begin{tabular}{lll}
\hline & $\begin{array}{l}\text { 8-Hydroxy- } \\
\text { quinoline }\end{array}$ & $\begin{array}{l}\text { Poly(ethyleneimine) } \\
\text { 8-hydroxyquinoline }\end{array}$ \\
\hline Color of complex & orange & orange \\
$\mathrm{pH}$ & $3-11.2$ & $2-5$ \\
$\lambda_{\max }(\mathrm{nm})$ & 435 & 424 \\
$\varepsilon\left(1 \cdot \mathrm{mol}^{-1} \cdot \mathrm{cm}^{-1}\right)$ & $7.15 \cdot 10^{3}$ & $1.06 \cdot 10^{4}$ \\
Analytical range $(\mathrm{mg} / \mathrm{l})$ & $0.5-15$ & $0-2.5$ \\
Interfering ion & $\mathrm{NH}_{4}^{+}$ & $\mathrm{NH}_{4}^{+}$ \\
Method & extraction & direct \\
\hline
\end{tabular}

Table II. Comparison of experimental data of the Pd(II) complexes of 8-hydroxyquinoline and poly(ethyleneimine)-bound 8-hydroxyquinoline.

a Adopted from ref. [16]. 


\section{Effect of tartaric acid}

Tartaric acid is a ligand which complexes many metal ions and most of the complexes are colorless. The influence of tartaric acid on the complexation of the 8-hydroxyquinoline polymer and palladium(II) was studied as a masking reagent in order to eliminate the influence of interfering metal ions. The results presented in Fig. 5 show that less than $1.0 \mathrm{wt} .-\%$ tartaric acid solution did not influence the formation of the colored polymer complex and the absorbance was not changed in that range.

Consequently, 0.5 wt.- $\%$ tartaric acid was chosen for the experiments.

\section{Effects of the concentration of palladium(II)}

The plot of absorption versus concentration of palladium(II) shows a linearity of this relationship between 0 and $25 \mu \mathrm{g} / 10 \mathrm{ml}$ and the molar extinction coefficient was $1.06 \cdot 10^{4} 1 \cdot \mathrm{mol}^{-1} \cdot \mathrm{cm}^{-1}$ at the maximum wavelength of $424 \mathrm{~nm}$ (Fig. 6).

The corresponding molar extinction coefficient of the colored complex of 8-hydroxyquinoline with palladium(II) is $7.1 \cdot 10^{3} \cdot 1 \cdot \mathrm{mol}^{-1} \cdot \mathrm{cm}^{-1}$ [13]. This indicates that by the attachment of the ligand to the polymer the sensitivity of the ligand for metal ions was more than $45 \%$ higher. The reason for that is an enlargement of the size of the ligand molecule by attachment of the ligand to the polymer chain with a consequently increased surface of its cross-section. Therefore, also the area of extinction was increased. The dependence of absorbance was not linear in the saturation range with palladium(II) ions. That corresponds to a concentration limit of $25 \mu \mathrm{g} / 10 \mathrm{ml}$ palladium(II).

\section{Effect of time}

The measurements of the time dependence are illustrated in Fig. 7.
The results indicate that the absorbance of the colored complex was not changed for 40 minutes and therefore stable for this time period.

\section{Effect of other ions}

Like the monomeric 8-hydroxyquinoline POX complexes many metal ions and forms colored complexes. In the experiments mentioned above the influence of tartaric acid as masking reagent for the complexation of the polymer with palladium(II) was also investigated. The results clearly show that a concentration range of $0-1.0 \mathrm{wt} .-\%$ tartaric acid did not disturb the complexation. The influence of other ions was also studied in the presence of 0.5 wt.- $\%$ tartaric acid. The results obtained reveal that the presence of $0.002-0.02$ $\mathrm{mg} \cdot \mathrm{ml}^{-1}$ of other ions did not interfere with the formation of the polymer-palladium(II) complex (Table III).

In conclusion, it can be stated that poly(ethyleneimine) 5-sulfonyl-8-hydroxyquinoline complexes strongly palladium(II) ions in a $\mathrm{pH}$ range of 2.0-5.0. The polymer-bound 8-hydroxyquinoline behaves the same way as the low-molecular-weight analogue reagent. The color complex formed with palladium(II) is stable for 40 minutes according to the spectrophotometric measurements. The macromolecular 8-hydroxyquinoline derivative exhibits an increased sensitivity towards palladium(II) compared to the low-molecular analogue. It has potential application as a selective polymeric analytical reagent for the determination of palladium(II). In addition, the general application of this concept could lead to the development of more sensitive analytical reagents.

R. Z. thanks the Hanns-Seidel-Stiftung for a grant. Financial support from the Fonds der Chemischen Industrie is gratefully acknowledged.

\begin{tabular}{llllll}
\hline $\begin{array}{l}\text { Concentration } \\
(\mathrm{mg} / \mathrm{ml})\end{array}$ & & & & & \\
\hline 0 & $\mathrm{NH}_{4}^{+}$ & & & & \\
0.002 & $\mathrm{Fe}(\mathrm{III})$ & & & & \\
0.005 & $\mathrm{Al}(\mathrm{III})$ & & & & \\
0.01 & $\mathrm{Ca}(\mathrm{II})$ & $\mathrm{Cr}(\mathrm{III})$ & $\mathrm{Mn}(\mathrm{II})$ & $\mathrm{Co}(\mathrm{II})$ & $\mathrm{Au}(\mathrm{III})$ \\
0.02 & $\mathrm{Li}(\mathrm{I})$ & $\mathrm{Ba}(\mathrm{II})$ & $\mathrm{Ni}(\mathrm{II})$ & $\mathrm{Zn}(\mathrm{II})$ & $\mathrm{As}(\mathrm{III})$ \\
& $\mathrm{K}(\mathrm{I})$ & & $\mathrm{Pt}(\mathrm{IV})$ & $\mathrm{Cd}(\mathrm{II})$ & $\mathrm{As}(\mathrm{V})$ \\
& $\mathrm{Cs}(\mathrm{I})$ & & & $\mathrm{Hg}(\mathrm{II})$ & \\
\hline
\end{tabular}

Table III. No-effect concentration of other cations on the complexation of poly(ethyleneimine) 5-sulfonyl-8-hydroxyquinoline with palladium(II) in the presence of tartaric acid $(0.5$ wt. $-\%)$. 
[1] E. Tsuchida and H. Nishide. Adv. Polym. Sci. 24, 1 (1977).

[2] M. Griesbach and K. H. Lieser. Angew. Makromol. Chem. 90, 143 (1980).

[3] D. Wöhrle, Adv. Polym. Sci. 50, 45 (1983).

[4] S. N. Willie, R. E. Sturgeon, and S. S. Berman. Anal. Chim. Acta 149, 59 (1983).

[5] K. Geckeler, V. N. Pillai, and M. Mutter, Adv. Polym. Sci. 39, 65 (1981).

[6] K. Geckeler, G. Lange, H. Eberhardt, and E. Bayer. Pure Appl. Chem. (IUPAC) 52, 1883 (1980).

[7] K. E. Geckeler, E. Bayer, B. Y. Spivakov, V. M. Shkinev, and G. A. Vorobeva, Anal. Chim. Acta 189, 285 (1986).

[8] K. E. Geckeler, V. M. Shkinev, and B. Y. Spivakov. Angew. Makromol. Chem. 155, 151 (1987).

[9] K. E. Geckeler, E. Bayer, G. A. Vorobeva, and B. Y. Spivakov. Anal. Chim. Acta 230, 171 (1990).
[10] K. Geckeler, K. Weingärtner, and E. Bayer, in E. Goethals (ed.): Polymeric Amines and Ammonium Salts, p. 277, Pergamon Press, Oxford (1980).

[11] K. E. Geckeler, E. Bayer, V. M. Shkinev, and B. Y. Spivakov. Abstr. Pittsburgh Conf., New Orleans, p. 999 (1988)

[12] F. J. Welcher. Organic Analytical Reagents. Vol. 1, p. 264, Van Nostrand, Princeton, USA (1974).

[13] K. L. Cheng, K. Ueno, and T. Imamura (eds): CRC Handbook of Organic Analytical Reagents. p. 253, CRC Press, Boca Raton, USA (1982).

[14] L. D. Pannington and M. B. Williams. Ind. Eng. Chem. 51, 759 (1959).

[15] A. P. Novikov, V. M. Shkinev, B. Ya. Spivakov, B. F. Myasoedov, K. E. Geckeler, and E. Bayer. Radiochim. Acta 46, 35 (1989).

[16] H. Hashitani, H. Yoshida, and K. Motojima. Bunseki Kagaku 18, 136 (1969). 